\title{
KONSEP CRITICAL PEDAGOGY HENRY A. GIROUX
}

\author{
Ichwani Siti Utami \\ Fakultas Keguruan dan Ilmu Pendidikan, Universitas Pamulang \\ amiutami10@gmail.com \\ Adam Alfian \\ Fakultas Keguruan dan Ilmu Pendidikan, Universitas Pamulang \\ adamalfian1928@gmail.com
}

\begin{abstract}
This article to discuss the critical pedagogy Henry A. Giroux, trough a philosopichalhistorical approach with the type of literature study. Girouxis one of the thinkers as well as developing critical pedagogy, the author tries to describe the concept of critical pedagogy Henry A. Giroux in some of his works. Critical pedagogy is not the new discource in the scientific field of education in Indonesian, but the authors considers it necessary to reintroduce the concept of critical pedagogy, especially for those who focus on critical theory studies that have been developed by Frankfurt School. And describes the discourse of implementation of crtical pedagogy for the advancement of Indonesian education.
\end{abstract}

Keywords: Henry A. Giroux, critical pedagogy, education, frankfurt school

\author{
Jurnal Pendidikan Kewarganegaraan \\ Journal of Civics and Education Studies \\ The journal is published by Department of Civic Education \\ Faculty of Teacher Training and Education \\ Universitas Pamulang - Indonesia
}

Copyright $\odot 2017 \mid$ ISSN: 2302-0865 


\section{PENDAHULUAN}

Dewasa ini bangsa Indonesia sedang pada titik kulminasi menentukan akan berhasil atau tidak pergumulannya menggapai cita-cita untuk memajukan kesejahteraan umum, mencerdaskan kehidupan bangsa, dan ikut melaksanakan ketertiban dunia yang berdasarkan kemerdekaan, perdamaian abadi, dan keadilan sosial. Hal ini mungkin sangat menggelitik pemikiran kita yang ingin secara nyata melibatkan diri dalam merealisasikan cita-cita tersebut (F. Danuwinata dalam Freire, 2008:x).

Pendidikan sebagai salah satu instrument dari kemajuan masyarakat tidak boleh mengalami "kekeringan" gagasan, memunculkan kembali beragam wacana dan konsep alternatif dalam ruang pendidikan sebagai sebuah jawaban dalam mendobrak "ke-monotonan" literatur dalam ilmu pendidikan. Bagaimanamungkin cita-cita yang begitu progresif dari bangsa ini dapat tercapai, jika ruang-ruang ke-ilmuannya mengalami stagnansi gagasan dan wacana.

Pola-pola konservatif dan cenderung tertutup membuat kita menjadi enggan melihat realitas dunia secara luas, nyatanya, ruang-ruang pendidikan dibeberapa Negara maju (Eropa Barat, Skandinavia, dan Amerika Latin) justru telah membuat terobosan yang luar biasa, mulai dari kebijakan, konsep, serta implementasinya. Salah satu corak kemajuan yang dapat kita lihat dari kemajuan ini ialah konsep critical pedagogy yang pertama kali diperkenalkan oleh Paulo Freire.
Paulo Freire adalah salah satu tokoh pendidikan asal Recife, Brazil dan menjadi orang yang paling berpengaruh di Amerika Latin dalam merekontruksi pandangan-padangan pendidikan konservatif, ia memulai gagasannya melalui pendekatan filsafat materialismedialektis (salah satu landasan filosofis dari para Marxian), kemudian dengan pendekatan tersebut ia mencoba menkontruksi pemikirannya tentang pendidikan (F. Danuwinata dalam Freire, 2008:xxiii). Dengan menempatkan permasalahan sosial sebagai basis material (kelaparan, kemiskinanm, perbudakan, dan permasalahan kesenjangan lainya) sebagai titik keberangkatannya agar ruang-ruang pendidikan mampu menjadi pendobrak kekuasaan yang "tiran" dan otoriter. Serta dalam implementasinya Freire juga dalam "praksis" yang menurutnya adalah proses dialektis yang berjalan tiada henti antara aksi dan refleksi serta antara refleksi dan aksi (Freire, 2008:xxi).

Gagasannya terbukti berhasil dengan berbagai pengakuan dunia, pada 1965 ketika Freire berada di Cile programprogamnya yang direstui oleh Pemerintah Cile di bawah Presiden Eduardo Frel menarik perhatian internasional, khususnya UNESCO, sehingga negeri ini dianggap salah satu dari lima Negara di dunia yang sangat berhasil dalam mengatasi masalah tuna aksara dan tidak hanya terbatas disitu, Freire juga diminta menjadi penasihat dalam menata kembali pendidikan pertanian, yang menjadi tugas Lembaga Penelitian dan Latihan Agraria 
(ICIRA) bekerja sama denga FAO (Freire, 2008:xiv).

Pada dasarnya tujuan Freire dalam critical pedagogy adalah humanisme, Freire berusaha meradikalkan makna humanisme sehingga kejahatan-kejahatan struktural yang sering kali bersembunyi dibalik "kebijakan" dapat terungkap dan diatasi melalui pendidikan. Gagasan ini yang akhirnya mempengaruhi beberapa pemikir setelahnya seperti, Ivan Ilich, dan juga Henry A. Giroux, dalam karya-karya Giroux ia mencoba mengembangkan critical pedagogy dalam corak masyarakat modern dan postmodern. Penulis menganggap cukup menarik jika dalam ruang-ruang intelektual terutama bagi kita yang mendalami studi Ilmu Pendidikan untuk memperluas pengetahuan dan wacana kita tentang critical pedagogy, yang kali ini ialah pemikiran critical pedagogy Henry A. Giroux.

\section{METODE PENELITIAN}

Jenis Peneltian dalam artikel ini adalah penelitian kepustakaan, yaitu penelitian yang dilakukan dengan cara mempelajari, menelaah, dan memeriksa bahan-bahan kepustakaan memiliki relevansi dengan objek penelitian (Yayasan Obor Indonesia, 2004:3). Secara sumber berasal dari perpustakaan, jurnal, naskah-naskah lain yang berkaitan dengan objek penelitian. Dalam penelitian ini penulis menggunakan metode deskriptifanalitis yang ingin mencoba mendeskripsikan konstruksi critical pedagogy Henry A. Giroux.
Dalam penelitian ini penulis juga menggunakan pendekatan historisfilosofis (Yayasan Obor Indonesia, 2004:9), untuk mencari pertalian pemikiran lain yang mempengaruhi pemikiran ciritical pedagogy Henry A. Giroux , melalui bahan-bahan yang telah dikumpulkan, dipilah, dan dipelajari.

\section{PEMBAHASAN}

\section{Critical Pedagogy}

Critical pedagogy dipahami sebagai teori dan praktik pendidikan yang didesain untuk membangun kesadaran kritis peserta didik(Totot Suharto, 2012: 280). Menurut Freire critical pedagogy adalah Suatu bentuk pedagogi yang harus diolah bersama, bukan untuk, the oppressed (sebagai individu maupun anggota masyarakat secara keseluruhan) dalam perjuangan tanpa henti untuk merebut kembali kemanusiaan (Toto Suharto, 2012: 281). Pedagogi ini menjadikan penindasan dan sebab-sebabnya sebagai bahan refleksi bagi the oppressed, dan dari refleksi ini akan lahir perlunya terlibat dalam perjuangan bagi kebebasannya. Dalam perjuangan itu pedagogi akan dibuat dan diperbaiki. Menurut Lankshear dkk., critical pedagogy yang dikembangkan Freire, melalui berbagai karyanya, merupakan suatu konsep umum tentang critical practice di dalam dan sekitar pendidikan. Konsep ini mencakup kajian yang lebih luas mengenai strukutur dan relasi pendidikan, yang menjadi dasar bagi pembentukan kehidupan masyarakat secara luas (Toto 
Suharto, 2012: 281). Paulo Freire (1998:

9) mengatakan:

Critical Pedagogy is a pedagogy of action that aims to an informed transformation of society through a praxis involving the articulation between theory and practice, thinking and doing. In other words, critical action is an informed, reflective, engaged and creative practice.

Ciritical pedagogy sendiri bertujuan untuk mentransformasikan informasi tentang masyarakat melalui praksis yang melibatkan artikulasi antara teori dan praktik, berpikir dan melakukan. Kesatuan teori dan praktik dalam critical pedagogy tidak dapat dipisahkan, jadi yang terdapat dalam konsep critical pedagogy bukanlah sekedar retoris, melainkan tindakan nyata yang bersumber dari realitas dunia. Sedangkan menurut Henry A. Giroux (2011: 6) secara fungsional mengatakan dalam salah satu karya besarnya critical pedagogy adalah;

Critical pedagogy in my work functions as a lens for viewing public and higher education as important sites of struggle that are capable of providing students with alternative modes of teaching, social relations, and imagining rather than those that merely support the status quo.

Dalam arti ini Giroux menempatkan bahwa critical pedagogy merupakan sebuah lensa untuk mengamati masyarakat dan pendidikan tinggi sebagai sebuah tempat perjuangan yang sanggup menyediakan para pelajar (dalam artian luas) dengan model-model pengajaran alternatif, relasi sosial, dan imajinasi daripada sekedar mendukung status quo.

\section{Pendidikan dalam Perspektif Critical Pedagogy}

Menurut Paulo Freire pendidikan adalah praktek pembebasan, memberikan tekanan khusus pada pentingnya permunculan kesadaran kritis sebagai penggerak emansipasi kultural (Dhakiri, 2000: 36). Kemudian, Pendidikan Menurut Henry A. Giroux pada hakikatnya adalah sebagai wahana mengasah sikap kritis dan politis untuk menciptakan demokrasi yang sesungguhnya, bukan demokrasi semu dalam masyarakat kapitalis-elitis (Rukiyati, 2011: 50). Dalam konteks ini definisi pendidikan lebih ditenkankan pada aspek-aspek sosial yang mana pendidikan dilihat sebagai suatu wahana untuk mengasah kesadaran kritis dalam setiap diri manusia, Freire dan Giroux tidak mendefinisikan pendidikan sebagai suatu kegiatan yang pasif, Freire menerapkan konsep dialogis dalam proses pendidikan yang mana ini berasal dari kritiknya terhadap model pendidikan "gaya bank". Sedangkan Giroux sendiri melihat pendidikan menggunakan pisau analisa culture studies, sehingga dalam padangannya terdapat implikasi yang kuat antara proses pendidikan terhadap laju kehidupan masyarakat.

\section{Prinsip-Prinsip Critical Pedagogy}

Pendidikan kritis yang ditawarkan oleh para pengusungnya menyakini bahwa adanya muatan politis dalam setiap 
aktivitas pendidikan, tidaklah merepresentasikan satu gagasan tunggal dan homogen. Menurut Agus Nuryanto yang terpenting dalam hal ini adalah para pendukung pendidikan jenis ini memiliki maksud yang sama, yaitu memberdayakan kaum tertindas dan mentransformasikan ketidakadilan sosial yang terjadi di masyarakat melalui pendidikan, pemerasan, penindasan, dan kekejaman yang dilakukan oleh kaum penindas (Toto Suharto, 2012: 284).

Dalam prinsipnya, sebagaimana yang telah dinyatakan oleh para tokoh pendidikan kritis diantaranya, Freire, Giroux, Apple, dan McLaren. Yaitu;

1. Untuk mengembalikan fitrah ontologis manusia di atas, pendidikan kritis menolak pendidikan gaya bank, dan menggantikannya dengan pendidikan hadap masalah yang dilakukan dengan metode yang menekankan komunikasi dialogis.

2. Kurikulum pendidikan bukan hanya menekankan pada academic achievement, tapi lebih diarahkan pada pembangunan aspek epistemologis, politis, ekonomis, ideologis, teknis, estetika, etis, dan historis.

3. Oleh karena institusi sekolah merupakan arena produksi budaya, maka penggunaan konsep hegemoni dan ideologi sebagai pisau analisis dalam pendidikan kritis merupakan hal esensial.

4. Pendidikan kritis menilai posisi pendidik adalah sebagai pekerja budaya yang berperan sebagai intelektual transformatif.

5. Pendidikan kritis menyediakan wacana teoritis untuk memahami bagaimana kuasa dan pengetahuan, satu sama lain, dapat menginformasikan di dalam produksi, resepsi dan transformasi identitas sosial budaya.

6. Pendidikan kritis menemukan bahwa secara pasti tidak ada pengetahuan yang bersifat netral yang dapat membentuk kesadaran manusia.

7. Pendidikan kritis secara revolusioner menggunakan dunia secara reflektif untuk mewujudkan praxis transformasi pengetahuan melalui kritik epistemologis.

\section{Biografi Singkat Henry A. Giroux}

Henry A. Giroux lahir pada 18 september 1943 di Rhode Island, Amerika Serikat. Anak dari imigran kelas pekerja asal Kanada Alice dan Armand Giroux, pada 1977 mendapat gelar Doctor dari Universitas Carnegie Mellon, Pittsburgh Amerika Serikat. Sebelumnya ia pernah menjadi guru sekolah menengah di Barrington, Rhole Island selama enam tahun dari 1968-1975. Sepanjang karirnya ia pernah menempati beberapa posisi dibeberapa Universitas; Universitas Boston, Universitas Miami, dan Universitas Penn State. Pada tahun 2005 Giroux mulai menjabat sebagai ketua Jaringan TV Global dalam Studi Bahasa Inggris dan Budaya Universitas McMaster di Hamilton, Ontario. Giroux telah 
menerbitkan lebih dari 60 buku dan 400 artiker, yang diterbitkan secara luas di seluruh literature studi pendidikan dan budaya.

Dari sekian banyak karyanya, menurut penulis terdapat beberapa karya penting seperti buku yang ia tulis pada tahun 2011 On Critical Pedagogy, 1991 Postmodern Education: Politics, culture, and Social Criticism, dan 1998 Teachers as Intellectual: Toward a Critical Pedagogy Learning, bukubuku inilah yang memperlihatkan bagaimana pemikiran Giroux mengenai Critical Pedagogy dalam pendidikan.

\section{Pendidikan dalam Persepktif Henry A. Giroux}

Dalam On Critical Pedagogy, Giroux (2011: 75) melihat bahwa Pendidikan (secara institusi) bukanlah lembaga yang otonom, Giroux, sebagaimana dalam critical pedagogy-nya melihat pendidikan sebagai;

...,education is a form of political intervention in the world and is capable of creating the possibilities for social transformation.

Dalam pandangan Giroux pendidikan merupakan sebuah bentuk intervensi politis di dunia yang sanggup menciptakan kemungkinan-kemungkinan perubahan sosial. Culture studies sebagai pisau analisa dari pemikiran Giroux mengenai pendidikan dalam mengembangkan critical pedagogy-nya membuat Giroux (2011: 9) dalam pandangannya dalam pendidikan sebagai;

...,critical education is central to

politics in that it provides the formative culture that produces engaged citizens and makes social action and democracy possible.

Giroux melihat pendidikan sebagai pendidika kritis sejalan dengan konsepnya mengenai critical pedagogy, Grioux melihat bahwa pendidikan adalah pusat politik yangmana pendidikan menyediakan budaya formatif yang melibatkan masyarakat dan membuat social action dari demokrasi menjadi mungkin.

Pengaruh dari mahzab Frankfurt sangatlah besar terhadap pemikiran Giroux, melanjutkan tradisi teori kritis yang telah dibangun oleh para pemikir sebelumnya, seperti Theodore Adorno, Max Horkheimer, Jurgen Habermas dan lain-lain yang tergabung dalam Frankfurt School. Menurut Bronner dalam teori kritis kebebasan tidak terkait dengan tatanan atau sistem pikiran tertentu. Teori kritis senantiasa mempertanyakan asumsi dan tujuan tersembunyi dari sebuah pemikiran yang bertolak belakang dengan kenyataan yang ada. Teori kritis menegaskan bahwa pemikiran harus menanggapi masalah baru dan melihat kemungkinan baru demi pembebasan diri dari kungkungan sejarah.

Dalam arti sempit, teori kritis adalah penelitian interdisipliner yang dilakukan oleh anggota mazab Frankfurt dan para penerusnya. Perubahan sosial yang ideal harus dicapai berdasarkan penelitianpenelitian terutama kajian yang didasarkan pada teori perubahan social yang dikemukakan oleh Mark. Sedangkan dalam arti luas, teori kritis adalah istilah umum untuk mewadahi semua proyek penelitian dalam ilmu social dan humaniora yang menekankan keterlibatan 
politis (Bronner, 2011: 47). Pada dasarnya teori kritis, salah satunya, berorientasi pada kemajuan kehidupan manusia melalui perubahan sosial, bentuk interdisipliner ini yang membuat teori kritis mampu diakomodasikan oleh Giroux dalam dunia pendidikan.

Giroux juga menaruh perhatian pada dominasi-dominasi penguasa, atau yang dalam istilah Antonio Gramsci disebut sebagai Hegemoni, pengaruh Gramsci dalam pemikiran Giroux (2011: 61) yaitu thinking like Gramsci; reclaiming the struggle over schooling.

"Schooling, in Gramsci's terms, was always part of some larger ensemble "of relationships headed and moved by authority and power." Hence, the struggle over schooling must be inextricably linked to the struggle against abusive state power, on the one hand, and the battle for "creating more equitable and just public spheres within and outside of educational institutions."

Pendidikan sebagaimana kutip oleh Giroux dari Gramsci, merupakan bagian yang besar dari ensemble(rangkaian) hubungan yang dipimpin dan digerakan oleh otoritas dan kekuasaan (kelas dominan), karenanya perjuangan selama masa sekolah tidak dapat dipisahkan keterkaitannya dengan perjuangan melawan kekuasaan Negara yang kejam. Ini merupakan bagian yang dianggap penting oleh Giroux untuk menciptakan pelajar sebagai intelektual organik, bahwa tidak ada dikotomis antara kau intelektual dan rakyat.
Inilah critical pedagogy Giroux, melalui pendekatan culture studies, teori kritis, dan intelektual organik Antonio Gramsci. Analisis Giroux tentang kontradiksi pendidikan banyak menjelaskan berbagai distorsi terhadap praktik-praktik buruk pendidikan yang berorientasikan efisiensi ekonomis (Giroux, 1992:49). Menurutnya terjadi degradasi identitas institusi pendidikan dari institusi yang menyelenggarakan pendidikan publik menjadi pabrik kuli. Giroux menengarai banyak institusi pendidikan (institusi yang dimaksud dalam tesis ini khususnya Sekolah Menengah Atas) yang berubah orientasinya menjadi penyedia birokrat elit masyarakat dan pendukung kapitalisme modern melalui pasar kerja. Kontradiksi ini dalam pemahaman Giroux menjadi kegagalan lembaga pendidikan sebagai tranformasi terciptanya humanisasi kehidupan publik.

\section{Penerapan Critical Pedagogy di Indonesia}

Sebagaimana telah dijabarkan sebelumnya tentang konsep critical pedagogy Henry A. Giroux, perlu bagi penulis untuk memberikan relevansi sebagai suatu bentuk wacana implementasi dari konsep tersebut bagi pendidikan di Indonesia, khususnya dalam Pendidikan Kewarganegaraan, diskursus mengenai penerapan konsep critical pedagogy di Indonesia dalam mata pelajaran Pendidikan Kewarganegaraan bukan merupakan suatu hal baru, beberapa universitas di Indonesia telah banyak memproduksi wacana ini, seperti 
Universitas Negeri Yogyakarta, Universitas Pendidikan Indonesia, Universitas Gadjah Mada, Universitas Airlangga Surabaya, dan beberapa universitas lain yang memiliki konsen pada critical pedagogy.

\section{Terminologi}

Pendidikan

Kewarganegaraan harus dimaknai dalam konsep yang luas, hal ini didasarkan pada realitas bahwa pada abad 21 manusia menghadapi berbagai tantangan dan kehidupan yang cukup kompleks sehingga PKn memiliki posisi sebagai bagian dari kurikulum persekolahan yang bertujuan mengembangkan kemampuan peserta didik dalam merespon tantangan global yang mengarah pada ciri kontinum PKn pada titik maksimal yang mana menurut McLaughlin, yaitu thick, inclusive, activist, citizenship education, participate, process led, value based, interactive interpretation, more difficult to achieve and measure in practice (Setiarsih, 2017: 80).

Merujuk pada pola Jurgen Habermas yang mengkategorikan pengetahuan dalam tiga kategori yaitu teknis, praktis, dan emansipatoris maka untuk mewujudkan pembelajaran PKn kritis, Grioux mengemukakan konsep rasionalitas dalam tiga kategori yaitu rasionalitas teknis, rasionalitas hermeneutik, dan rasionalitas emansipatori (Grioux, 1980:81).

\section{Rasionalitas Teknis}

Rasionalitas teknis berhubungan dengan prinsip pengawasan dan kepastian yang menggunakan ilmu-ilmu alam sebagai model pengembangan teoritis. Dengan asumsi ilmu alam maka pengetahuan dimulai dari hal yang konkrit dan dapat diuji secara empiris sehingga pengetahuan menjadi sebuah penelitian ilmiah yang objektif dan bebas nilai. Implikasi model ini terhadap teori pendidikan adalah pengetahuan harus dipisahkan dari proses pembentukannya atau kerangka law like mode of thaught.

\section{Rasionalitas Hermeneutik}

Rasionalitas hermeneutik tidak menunjukkan produksi pengetahuan yang monologis namun lebih memusatkan perhatian dalam memahami pola interaksi simbolis yang komunikatif. Rasionalitas ini berkaitan dengan penafsiran pembuat teks atau pembaca teks terhadap suatu teks. Oleh karena itu, manusia bukan makhluk pasif yang sekedar menerima informasi namun makhluk aktif yang memiliki hak menafsirkan informasi karena bahasa bukanlah media transparan yang dapat menyampaikan ide-ide tanpa distorsi (Setiarsih, 2017: 83). Implikasi rasionalitas hermeneutik dalam pembelajaran PKn adalah membantu pendidik memaknai realitas dibalik teks untuk mengungkap dimensi tersembunyi yang timbul dari muatan pengetahuan dan hubungan di dalam kelas. Pengetahuan tidak disampaikan secara indoktrinasi namun disampaikan secara dialogis yang bertujuan mendorong kemampuan peserta didik untuk mengeksplorasi dan mengartikulasikan pengalaman mereka sendiri. Giroux berpendapat bahwa yang mendasari logika kurikulum tersembunyi dan sekolah adalah struktur tersembunyi tentang relasi antara kelas dan budaya (Hidayat (2013) dalam Setiarsih, 2017: 
84). Dimensi tersembunyi yang tidak direncanakan, tidak diprogramkan dan tidak tertulis namun turut berpengaruh dalam proses pendidikan itulah yang disebut sebagai kurikulum tersembunyi (hidden curriculum).

\section{Rasionalitas Emansipatoris}

Rasionalitas emansipatori didasarkan pada prinsip, kritik dan tindakan yang bertujuan merefleksikan diri dengan aksi sosial yang telah dirancang. PKn dalam model rasionalitas emansipatori harus menghasilkan dan menekankan pentingnya hubungan sosial. Dengan demikian, proses pembelajaran bertujuan untuk mengritisi pengetahuan dan mendemistifikasi kepentingan ideologis dibalik konstruksi realitas sosial sehingga pengetahuan emansipatoris dapat mendorong peserta didik menggunakan self reflection untuk mentransformasi dirinya menjadi subjek yang independen dan merdeka (Setiarsih, 2017: 84). Madeleine MacDonald menyatakan bahwa asumsi yang mendasari sebagian besar teori "reproduksi" adalah pendidikan yang berperan memediasi antar kesadaran pada masyarakat (Giroux, 1980: 347). Teori ini mempertahankan bahwa aturan yang mengatur perilaku sosial, moral, dan keyakinan dari tingkat struktur ekonomi makro dan politik diperoleh melalui pengalaman bekerja, proses pendidikan, dan lingkungan keluarga. Setiap orang sadar pada kondisi masyarakat disekitarnya. Pemahaman dan sikap terhadap tatanan sosial adalah kesadaran individu yang diharapkan mampu membawa perubahan.
Guna menciptakan Pendidikan Kewarganegaraan transformatif guru harus bertindak sebagai pendidik transformatif yang memandang proses pembelajaran tidak hanya bertujuan untuk membantu peserta didik memperoleh tingkat kompetensi kognitif yang tinggi namun juga bertujuan untuk mewujudkan peserta didik yang mampu menjadi warga negara kritis, aktif dan bertanggungjawab. Pendidik transformatif harus menempatkan pendidikan sebagai productive force yaitu media mobilitas sosial bukan reproductive force. Selain itu, pendidik transformatif juga harus membantu mengembangkan agensi peserta didik, senantiasa menghadapkan teks-teks normatif kurikulum ke dalam realitas sosial dan memandang perlunya konsep pendidikan sebagai language of critique dan language of possibility dimana pendidikan menjadi media kritis atas realitas sosial dan menawarkan kemungkinan dikembangkannya wilayah publik yang demokratis (Setiarsih, 2017: 85).

\section{KESIMPULAN}

Bahwa pendidikan dalam pandagan Henry A. Giruox dengan konsep critical pedagogy yang ia kembangkan, teridiri dari Cultture studies, teori kritis, Demokrasi, pembebasan, dan intelektual organic yang berorientasi pada transformasi sosial, serta pendidikan seharusnya diperuntukan sebagai wahana mengasah kemampuan kritis setiap manusia dengan melihat realitas dunia, bahwa dalam relasi kekuasaan dan 
ekonomi, begitupun dominasi diciptakan untuk menindas dan menguasai secara politik dan budaya.

Giroux melihat bahwa pendidikan bukanlah suatu lembaga yang otonom, dan di dalamnya saling berkelindan ideologi yang didasari dari berbagai macam aspek, sehingga menurutnya pendidikan kritis sangat diperlukan sebagai counter content dari model pendidikan yang telah ada sebelumnya, dengan memanfaatkan ruang-ruang pendidikan dan ruang publik sebagai satu kesatuan bagi transformasi sosial.

\section{Saran}

Bagi penulis, keterlibatan aktif setiap elemen dalam masyarakat dalam mewujudkan cita-cita bangsa Indonesia merupakan suatu faktor penting, pendidikan yang di dalamnya terdapat banyak simpul dan latar belakang, mampu menjadi pendobrak "gagasan" alternatif yang lebih revolusiner.

Studi-studi literasi dan telaah pemikiran dirasa sangat perlu ditingkatkan dalam memajukan pendidikan Indonesia. Kesenjangan sosial merupakan permasalahan yang harus dipecahkan oleh para pelaku pendidikan.

\section{REFERENS|}

Ari, S. (2017). Diskursus Pendidikan Kritis (Critical Pedagogy) dalam Kajian Pendidikan Kewarganegaraan. Citizenship: Jurnal Pancasila dan Kewarganegaraan, Vol. 5 No. 2, h. $76-$ 85.
Bronner, S. (2011). Critical Theory: A very short introduction. New York: Oxford University Press.

Dhakiri, H. M. (2000). Paulo Freire, Islam dan Pembebasan. Jakarta: Jembatan Pena.

Toto S. M. (2012). Pendididikan Kritis Dalam Perspektif Epistemologi ISlam (Kajian atas Prinsip-Prinsip Dasar Pendidikan Kritis). Conference Proceedings, Annual International Conference on Islamic Studies, 274295.

Freire, P. (1998). Teachers as Cultural Workers. Boulder: Westview Press.

Freire, P. (2008). Pendidikan Kaum Tertindas. Jakarta: Pustaka LP3ES.

Giroux, H. (1980). Critical Theory and Rationality in Citizenship Education, Curriculum Inquiry. Boston: Boston University Press.

Giroux, H. (1992). Cultural Workers and The Politics of Educations. New York: Rotledge.

Giroux, H. (2011). On Critical Pedagogy. New York: International Continuum Publishing.

Rukiyati. (2011). Konsep Pendidikan Menurut Henry A. Giroux (Suatu Tinjauan Filsafat). Yogyakarta: Universitas Negeri Yogyakarta.

Yayasan Obor Indonesia. (2004). Metode Penelitian Kepustakaan. Jakarta: Yayasan Obor Indonesia. 